\title{
The Prediction of High School Girls' Happiness Based on Their Educational Major and Their Mothers' Gender Stereotypes
}

\author{
Khadijeh Abolmaali ${ }^{*}$, Tayebeh Ghafari'1, Bita Ajilchi ${ }^{2}$ \\ ${ }^{1}$ Department of Psychology, Roudehen Branch, Islamic Azad University, Roudehen, Iran \\ ${ }^{2}$ Department of Psychology, Science and Research Branch, Islamic Azad University, Tehran, Iran \\ Email: sama.abolmaali@gmail.com
}

Received 31 January 2014; revised 28 February 2014; accepted 7 March 2014

Copyright (C) 2014 by authors and Scientific Research Publishing Inc.

This work is licensed under the Creative Commons Attribution International License (CC BY).

http://creativecommons.org/licenses/by/4.0/

(c) (i) Open Access

\begin{abstract}
Happiness related to an individual's happy perception, life satisfaction, and ability creates a balance between positive and negative feelings and leads to better functioning in life. Psychologists believe that the family plays a role in the explanation of happiness. In this regard, researchers have paid attention to the mother's stereotypical beliefs and their effect on the mother's behavior and her parenting style. The purpose of this research was to predict girls' happiness based on their educational fields and their mothers' gender serotypes. The statistical population included those student girls who were educated in high-school science and mathematics in Tehran in 2012. Random-cluster method was applied to select the samples. 243 participants completed a questionnaire on happiness and gender beliefs. Data were analyzed by hierarchical multiple regression. The results showed that mothers' gender stereotype can predict happiness in girls. Also the educational field can predict girl's happiness. The results of this research can be used by parents, educational psychologists and school counselors.
\end{abstract}

\section{Keywords}

Happiness, Gender Stereotypes, Educational Field

\footnotetext{
*Corresponding author.
}

How to cite this paper: Abolmaali, K., Ghafari, T., \& Ajilchi, B. (2014). The Prediction of High School Girls' Happiness Based on Their Educational Major and Their Mothers' Gender Stereotypes. Advances in Applied Sociology, 4, 121-127. 


\section{Introduction}

In the science of psychology, the emotions are investigated in both negative and positive fields. These emotions are happiness, satisfaction, love, relaxation and enjoyment (Argyle, Martin, \& Crosland, 1989). Happiness is one of the positive aspects of the emotions that positive psychologists focus on and emphasize its potentiality (Seligman, 2005). Happiness has a positive impact on the perceptions, recognition and social interactions of a community (Carr, 2004). In terms of the viewpoint of positivism, happiness can be investigated in the subjective well-being field. Seligman (2005) considers the happiness as a mental emotion or mood fluctuated by positive excitants and originating from enjoyment or satisfaction. Schwarz and Strack (1991) state that the reports of people regarding happiness and satisfaction can be subject to the judgment of their emotional moods; thus, emotional moods are being affected by the emotional and cognitive mechanisms and based on this. The happiness process requires both emotional and cognitive elements. During the last decades, the attention of psychologists towards the predicting of happiness factors has increased significantly. In some studies, the relationship of demographical features such as age (Safari, 2007), gender and education (Keshavarz \& Vafaieeian, 2007), and marital status (Alipour, Ezheiee, \& Motieeian, 2000) have been investigated. Khosravi, Ghomrani, \& Bardideh (2010) found that students of humanistic majors have the highest levels of happiness in comparison to engineering and technical majors. Safari (2010) showed that differences between people with various educational majors and different ethnic backgrounds are not significant in the score of happiness. Keshavarz \& Vafaieeian (2007) found that the family and social relations can also predict happiness. Furnham \& Cheng (2000) also found that the authoritative style of the education is the main predictor of the happiness. Berman \& Small (2012) stated that self-esteem can be considered as one of the basic predictors of the happiness, playing a median role in representing the process of happiness. Interest in the self and self-esteem can motivate people towards a happy life. People with high self-esteem value their life and try to enjoy their lives.

Four main growth factors have been introduced in relation to the effective agents on people's growth in different dimensions, such as emotional growth (Bronfenbrenner, 1979, quoted in Schlock \& Alonso, 2002). They are considered to be the following: microsystems, mesosystems, exosystems and choronosystems. Microsystems can have a rapid influence on important locations such as the house, and co-age groups at schools; mesosystems are the development of microsystems, and exosystems are the background factors such as neighborhood, social services and the interaction between different microsystems (for example, the interaction between house and school). A macrosystem is a combination of institutional patterns of culture or sub-cultural integrations such as political, legal, educational, social and economic systems, and the microsystem, mesosystem and ecosystem are its objective demonstration, influencing people's lives indirectly. Belsky (1980) added an extra system to Brenner's system and called it the ontogeny system (personal phenomenon). This system includes the interpersonal variables, personal differences in self-esteem, physical activity and multiple systems.

The cognitive well-being of children is determined in multiple cases by the personal factors. Although the children's experiences can be also influenced by various systems, the happiness of adolescents can appear at the ontogeny and microsystem levels (Huebner, Gilman, \& Furlong, 2009).

Of course it seems that the macrosystem is an important factor influencing people's mental well-being and happiness. The effective factors of people's well-being are different in the different cultures; therefore, the indices of being good are also different among different cultures. Hence, a complete image of being good can encompass the culture, gender and growth considerations of children and adolescents. So, it can be stated that people live in an integration system in terms of local ethnography issues. These systems can influence the cognitive, emotional, social and physical abilities of people, forming their self-esteem and influencing their happiness. Indeed, self-esteem and personal identity play key roles in people's happiness. The social identity is the most essential part and element of personal identity, being related to both female and male genders in this regard. Gender roles are subject to a collection of expectations, and the men's and women's behaviours are based on this issue (Jackson, 1998, quoted in Zohrehvand, 2006). These roles are the reflections of a social behavior that both genders can or cannot challenge in a community (Zibaieenezhad, 2009). Based on the two dimensional model of Bem, everyone may have three types of personality: female, male, and androgenic. The male personality is found in those men and women who achieve higher scores in the next step, giving male-based traits in this case. The female personality is related to those people in whom female traits appear higher than male. The androgen personality or two-gender trait is accorded to those people who achieve both male and female scores (Zhang et al., 2001, quoted in Akbari Dehkordi, Mohtashemi, \& Hassanzadeh, 2012). Children can experience 
different activities, opportunities, praises and punishments and guidelines from their parents through their social issues; the attitudes of the children towards gender are a reflection of the gender roles that the culture of a society expects to be applied in this regard. These attitudes influence people's behavior. In general, these attitudes and behaviors are first learned at home, and further upgraded through the school environment as well as mass media; however it seems that learning gender roles happen mostly in the family. In fact, the parents can directly or indirectly transmit their gender roles to their children; these roles may bring with them some gender stereotypes (Witt, 2000). Some features are often considered to be male, such as leadership, power, intelligence, ability, and brevity, and other features are attributed to women, such as being simple, intimate, and passive (Ifgebesan, 2010; Akbari Dehkordi et al., 2011). Such beliefs have been called stereotype-based gender beliefs; stereotypes are mental perceptions that may be reflected in attitudes and may prejudice the view of female or male traits (Martin \& Halverson, 1981). Indeed, stereotypes are subjected to gender, including cultural beliefs about what the gender roles have to be in this regard. These stereotypes are not reflective of the realities but they are the origin of the beliefs and common behavioral attitudes of men and women, inducing the frame-based imagination of the culture (Zohrehvand, 2006). The Theory of Planned Behavior (TPB) states that gender beliefs influence the behavior (Ajzen, 1991). Concentration on the target is a kind of readiness for a special behavior; that is, personal behaviors can be determined by personal motivation, social support and perceived behavioral control (Ifegbesan, 2010). Hence, it can be stated that the gender beliefs of mothers affect their behavior towards their children and have an impact on their happiness. Some studies have been carried out in the class environment in relation to gender stereotypes; for example, gender stereotypes and educational progression (Watt \& Bornbolt, 1994; Powell, Batterfield, \& Parent, 2002; Munawar, 2004; Witt, 2000). There have been other studies that have also investigated the relationship between adaptation and mental health along with people's gender beliefs (Wells, 1980; Taylor \& Hall, 1982; Whitely, 1983; Bam, 1974, quoted in Zohrehvand, 2006). But these studies have been carried out in relation to parents' beliefs and gender stereotypes and their personality and psychic traits. The lack of research in this area with regard to the role of the mothers' beliefs and their impact on the child is the reason why this study was conducted.

Teaching and learning in schools have strong social, emotional, and academic components (Zins, Weissberg, Wang, \& Walberg, 2004). Happiness and education are, properly, intimately connected. Teacher relationship, participation in classroom, and extra-curricular activities could improve learning emotion in schools (Noddings, 2003). Various subjects can provide different learning experiences for students. Some academic tasks need collaborative learning, which leads to more happy experience. It seems that assignments in science field need more collaborative activities, while math assignments are done mostly individually. In addition, teachers in science field can provide more varied examples that are relevant to everyday life. Korai Nouri (2012) has figured it out that compared to students of technical science such as engineering, students of humanities have greeter happiness. Also, Simian et al. (2012) showed that there is a significant difference between happiness among students who have been educated in different majors.

In this research, the main question represented is whether the adolescents' happiness can be predicted based on their parents' gender stereotypes.

\section{Method}

\subsection{Procedure}

The method of the present study is descriptive. 270 participants were randomly selected. The statistical population consisted of all high-school students in Tehran, who were educated in the fields of mathematics and science in 2013. For selecting of sample, the first, among the 22 districts of education of Tehran were randomly selected four districts; Then from each district was randomly selected two schools, and in per school was randomly selected two classrooms in math and two classrooms in science field, at then in each class students who were interested in participating in the study were studied.

One hundred 44 participants were studying natural sciences and 99 were studying mathematics and in total, $59.3 \%$ of the participants were studying natural sciences and $40.7 \%$ were studying mathematics. The mother's mean of age was 36 years, and level of their education were $28 \%$ diploma, $54 \%$ undergraduate and $13 \%$ postgraduate, and 5\% Ph.D. For data collection, the first students were tested, and their mothers were invited and were studied after obtaining informed consent. 


\subsection{Instruments}

\subsubsection{Oxford Happiness Questionnaire}

This questionnaire is applied to assess the students' happiness (Argyle, Martin, \& Lu, 1995). The reliability of this was reported 0.78 by using the test-retest method. Also, the construct validity of this scale was investigated by the Divergent method led by Francis et al. (quoted in Alipour et al., 2007) and the correlation of this test with the Beck depression test was 0.52 reported. The reliability coefficient of this test was reported by using alpha 0.93 by Alipour et al. (2007).

\subsubsection{Gender Beliefs Questionnaires (Zohrehvand, 2006)}

This questionnaire was based on the gender beliefs of Bem in 1974 as prepared by Zohrehvand (2006). She described five factors: completely male, fairly male, completely female, and fairly female and both genders. 46 traits were analyzed on 5062 high-school students in six provinces of the country, after factor analysis with varmix rotation. The five-degree scale was applied to measure the related scores in this study. The scoring is as follows: completely male $=1$, fairly male $=2$, both genders $=3$, fairly female $=4$ and completely female $=5$

Also in order to specify the stereotypical and non-stereotypical gender beliefs, the scoring scale is used as following:

Score 1 = completely male or completely female

Score 2 = fairly female and fairly male

Score 3 = both genders (no stereotype)

Based on this scoring method, when the scores are between 1 and 3, the person's gender beliefs tend to be non-stereotypical. Zohrehvand (2006) reported the reliability of the gender beliefs questionnaires using the Cronbach alpha coefficient in her research as 0.88 in this regard.

\section{Results}

The data obtained from 243 questionnaires was analyzed in this research. The descriptive indices of the study variables are given in Table 1 as following:

Table 1 shows the mean, standard deviation, distributive indices of variables (kurtosis and skewness) by separation of the educational majors. According to Table 1, the standard deviation of natural science field in happiness and mother's gender beliefs is less than mathematics field. Kurtosis and skewness show that the distribution of the data is almost normal.

In order to evaluate the research hypothesis, the parametric regression hierarchical method was applied. The research hypothesis was as follows:

Girls' happiness based on mothers' stereotype beliefs and their educational major is predictable.

The results of the regression analysis showed that in the first step, by entering the variable into the stereotype the degree of R and R2 is 0.127 and 0.016 , respectively. This is significant (sig $<0.05$ ).

According to Table 2, it can be stated that about $1.6 \%$ of the happiness variance can be represented by the mother's gender stereotypes. In the second step, the categorization variable of educational majors with two levels of natural sciences (code 1 ) and mathematics (code 0 ) were entered into the equation, representing that the related degree of R and R2 is 0.212 and 0.045 respectively is significant in this pavement (0.029). As a result, about $2.9 \%$ of the happiness variance is predictable by the educational major.

Table ANOVA showed that both steps have been specified between the linear combination of weight independent variables and its model, and the dependent variable has a significant relationship in this regard. (Due to the degree of $\mathrm{F}$ and significance level ( $\mathrm{sig}<0.0001)$ and its degree of freedom); Thus, in Table 2 the regression coefficients of every variable have been reported.

Based on the above-mentioned tables, it can be stated that there is a positive significant relationship between both variables so that by increasing the score of gender beliefs towards non-stereotypical ones, the score of girls' happiness will increase. In other words, the mothers' gender stereotypes can predict the girls' happiness. In addition, there is a positive significant relationship between educational field and happiness so that when the mathematics field (code 0 ) goes towards natural sciences field (code 1), the score of happiness will also increase; that is, the major has a relationship with happiness.

\section{Discussion}

Based on the results of the research, there is a positive significant relationship between gender stereotypes and 
Table 1. Descriptive indices of under-study variables in both natural and mathematics fields.

\begin{tabular}{ccccc}
\hline \multirow{2}{*}{ Major } & \multicolumn{3}{c}{ Descriptive indices } \\
& Variable & Mean & Std deviation & kurtosis \\
\cline { 2 - 5 } Natural sciences & Happiness & 73.99 & 12.62 & 0.005 \\
& Gender beliefs & 159.22 & 38.06 & -0.569 \\
\multirow{2}{*}{ Mathematics } & Happiness & 70.21 & 15.46 & 0.456 \\
& Gender beliefs & 160.58 & 41.41 & -1.123 \\
\hline
\end{tabular}

Table 2. Regression coefficients of between mother’s gender stereotypes, educational major and their interaction.

\begin{tabular}{|c|c|c|c|c|c|}
\hline \multirow[b]{2}{*}{ Degree } & \multicolumn{5}{|c|}{ Regression coefficients } \\
\hline & $\begin{array}{c}\text { Non-standard regression } \\
\text { coefficients }\end{array}$ & Standard error & $\begin{array}{l}\text { Standard regression } \\
\text { coefficients }\end{array}$ & $\mathrm{T}$ & Sig \\
\hline Fixed degree & 69.22 & 1.35 & - & 51.18 & 0.0001 \\
\hline Gender stereotypes & 0.18 & 0.06 & 0.280 & 2.82 & 0.005 \\
\hline Major & 4.78 & 1.75 & 0.173 & 2.73 & 0.007 \\
\hline
\end{tabular}

happiness so that any increase in the mother's non-stereotype gender beliefs can cause an increase in happiness scores (high score in gender stereotype test indicated less stereotypical beliefs) In other words, gender stereotypes can predict happiness. Also, the happiness of natural sciences major students is higher than that of mathematic majors. In relation to the prediction role of the gender stereotypes, the results of Keshavarz and Vafaieeian (2007), Forenham and Cheng (2000) and Bremann and Small (2012) are coincident together. In relation to the prediction of happiness based on educational major the results of the present study are coincident with Khosravi et al. (2007) and Alipour, Ezheiee, \& Motieeian (2000) but are not comparable with the results of Safari's research (2010). In relation to the prediction of happiness with mothers' gender stereotypes on their girls' happiness, it can be stated that the beliefs and stereotypes of mothers have been designed based on behavioral theory (Ajzen, 1991). Indeed, parenting style impacts on the behaviors and beliefs of their daughters. Riahi (2007) found that there is a significant relationship between strict parents and acceptance of gender stereotypes. It seems parents having strong stereotypes beliefs treat their children more strictly. In addition, the mothers' gender stereotypes can affect children's entertainment and leisure times. The selection of an activity type for girls and its limitations can caused is satisfaction for the girls, reducing their happiness in this case. Lu (1999) believes that well-being elements and happiness are positive emotions, the lack of negative emotion and life satisfaction.

Negative beliefs and stereotypes can restrict girls, reducing their domain of happiness in this regard. These limited experiences confine social skills and this influences happiness, too (Amani \& Hadian-Hamdani, 2008). The interaction between mothers and daughters can be influenced by the mother's stereotype beliefs. Based on Belsky's viewpoint (1980) the ontogeny system can represent people's self-esteem and behaviors. Thus, the role of the family system and the mothers' stereotype beliefs can potentially be effective in the formation of happiness in children' future. In addition, a macro system is a combination of different cultural and sub cultural patterns such as legal systems and training, so that they can also impact on children's behavior. Also, the results of the present study indicated that the score of students' happiness in the natural sciences major is higher than that of mathematics majors. That is, there is a relationship between the major and happiness. However, the interactive effect of the major and gender stereotypes on happiness is not significant. It seems that the tasks of mathematics and the educational requirements of these students have restricted their happiness domain reducing their happiness as well. Therefore, this suggests that all consultants and psychologists should pay attention to the formation of girls' happiness and if necessary they have to be aware of the parents in this case. In addition it is recommended to consider social interactions in the school settings.

\section{Conclusion}

Based on the findings of this research, mothers who have gender stereotypical beliefs have daughters with less happiness. It can be said that they apply rigid and inflexible rules for training their daughters, and limit them in interpersonal communication with their peer group and in autonomy. Therefore it is recommended that counse- 
lors teach mothers the necessary information about the role of stereotypical beliefs on their daughters' happiness. Also scores in happiness among girls who are being educated in natural science were higher than those girls who are being educated in mathematics; this finding could stem from more flexible curriculum in the natural science major as compared to the mathematics major. Hence it is suggested that teachers, counselors and parents should provide happy experiences in schools and at home for girls who are being educated in mathematics major. The limitations of the study include the fact that the study was descriptive and researchers could not control the confounding variables such as socio-economic status, parenting styles, religious beliefs and commitment to traditions. On this basis, the findings cannot be interpreted as causal.

\section{References}

Ajzen, I. (1991). The Theory of Planned Behavior. Organizational Behavior and Human Decision Processes, 50, $179-211$. http://dx.doi.org/10.1016/0749-5978(91)90020-T

Alipour, A., Ezheiee, J., \& Motieeian, H. (2000). Happiness Functions and Immunity. Journal of Psychology, 4, $219-233$.

Amani, R., \& Hadian-Hamedani, R. (2008). Study of Effectiveness of Social Skills Training on Increasing the Degree of Students' Happiness. Collection of 4th Conference of Students' Mental Health, 35-38.

Argyle, M., Martin, M., \& Crossland, J. (1989). Happiness as a Function of Personality and Social Encounters. In J. P. Forgas, \& J. M. Innes (Eds.), Recent Advances in Social Psychology: An International Perspective (pp. 189-203). Amsterdam: North Holland, Elsevier Science.

Argyle, M., Martin, M., \& Lu, L. (1995). Testing for Stress and Happiness: The Role of Social and Cognitive Factors. In C. D. Spielberger, \& I. G. Sarason (Eds.), Stress and Emotion (pp. 173-187). Washington DC: Taylor \& Francis.

Berman, J.Z., \& Small, D.A. (2012). The Hedonic Benefit of Imposed Self Interest. Psychological Science, 23, $1193-1199$. http://dx.doi.org/10.1177/0956797612441222

Belsky, J. (1980). Child Maltreatment: An Ecological Integration. American Psychologist, 35, 320-335. http://dx.doi.org/10.1037/0003-066X.35.4.320

Carr, A. (2004). Positive Psychology: The Science of Happiness and Human Strength. New York: Brunner-Routledge.

Dehkordi, A. A., Mohtashami, M., \& Hassanzadeh, T. (2012). Study of Psychological Scale of Gender Role of Bem Short Form That Emphasizing on the Factorial Analysis in Iranian Population. Journal of Social Recognition, 1, 44-58.

Furnham, A., \& Cheng, H. (2000). Perceived Parental Behavior, Self-Esteem and Happiness. Social Psychiatry and Psychiatry Epidemiology, 35, 463-470. http://dx.doi.org/10.1007/s001270050265

Huebner, E. S., Gillman, R., \& Furlong, M. J. (2009). A Conceptual Model for Research in Positive Psychology in Children and Youth. In R. Gillman, E. S. Huebner, \& M. J. Furlong (Eds.), Handbook of Positive Psychology in Schools (pp. 3-9). New York: Routledge.

Ifegbesan, A. (2010). Gender-Stereotypes Belief and Practices in the Classroom: The Nigerian Post-Primary School Teachers. Global Journal of Human Social Science, 10, 29-39.

Keshavarz, A., \& Vafaieeian, M. (2007). Study of Effective Factors on Happiness. Journal of Applied Psychology, 2, 51-62.

Khosravi, S., Ghomrani, A., \& Bardideh, M. (2010). Study of Effective Factors on Students' Happiness, Journal of Educational Psychology, 21, 8-14.

Korai Nouri, R., Mocrie, A., Mohammadifar, M., \& Yazdani, E. (2012). The Study of Happiness \&Well Being: The Role of Different Factors for Them among Students of Tehran University. Journal of Education Psychology, 32, 3-41.

Lu, L. (1999). Personal or Environmental Causes of Happiness: A Longitudinal Study. Journal of Social Psychology, 139, 79-90. http://dx.doi.org/10.1080/00224549909598363

Martin, C. L., \& Halverson, C. F. (1981). Schematic Processing Model of Sex-Typing and Stereotyping in Children. Child Development, 52, 1119-1134. http://dx.doi.org/10.2307/1129498

Munawar, M. (2004). Gender Analysis of School Curriculum and Textbooks. Pakistan: UNESCO.

Noddings, N. (2003) Happiness and Education. New York: Cambridge University Press. http://dx.doi.org/10.1017/CBO9780511499920

Powell, G. N., Butterfield, D. A., \& Parent, J. D. (2002). Gender and Managerial Stereotypes: Have the Times Changed? Journal of Management, 28, 177-193. http://dx.doi.org/10.1177/014920630202800203

Riahi, M. E. (2007). Social Factors Effective on the Acceptance of Gender Stereotypes. Journal of Women in Development and Politics, 1, 50-83.

Safari, S. (2010). Study of Happiness Degree and Its Relationship with Demographical Variables among Students. Journal of Industrial Psychology, 2, 79-87. 
Seligman, M. E. P. (2005). The Positive Perspective on Youth Development. In D. L. Evans, E. B. Goa, R. E. Gur, H. Hendin, C. O’Brien, M. E. Seligman, \& T. Walsh (Eds.), Treating and Preventing Adolescent Mental Health Disorders: What We Know and What We Don't Know (pp. 498-527). Oxford: Oxford University Press.

Schalock, R., \& Alonso, M. A. V. (2002). Handbook on Quality of Life for Human Service Practitioners. Washington DC: American Association on Mental Retardation.

Schwarz, N., \& Strack, F. (1991). Evaluating One’s Life: A Judgment Model of Subjective Wellbeing. In F. Strack, M. Argyle, \& N. Schwarz (Eds.), Subjective Well-Being: An Interdisciplinary Perspective. Oxford: Pergamom Press.

Watt, H., \& Bornholt, L. (1994). Gendered Perception of Talent and Planned Participation in Mathematics. Australian Journal of Career Development, 3, 43-50.

Witt, S. (2000). The Influence of School and Reading Materials on Children’s. Gender Role Socialization: An Overview of Literature. Early Child Development and Care, 162, 1-7. http://dx.doi.org/10.1023/A:1007091121084

Zibaieenezhad, M. (2009). Identity and Gender Roles. Tehran: Office of Women's Study.

Zins, J. E., Weissberg, R. P., Wang, M. C., \& Walberg, H. J., Eds. (2004). Building Academic Success on Social and Emotional Learning: What Does the Research Say? New York: Teachers College Press.

Zohrehvand, R. (2006). Study of Psychological and Educational Status of Girl Students. Research Projects, Tehran: Institute of Education Studies. 